\title{
PREGNANCY-ASSOCIATED CHANGES OF SERUM BIOCHEMICAL VALUES IN LIPIZZANER BROODMARES
}

\author{
Boglárka VINCZE ${ }^{1,3^{*}}$, Orsolya KUTASI ${ }^{1}$, Ferenc BASKA ${ }^{2}$ and Ottó SZENCI ${ }^{3}$ \\ ${ }^{1}$ Department and Clinic of Equine Medicine, Faculty of Veterinary Science, \\ Szent István University, Üllő - Dóra major, H-2225 Hungary, ${ }^{2}$ Department of Pathology, \\ Faculty of Veterinary Science, Szent István University, Budapest, Hungary, \\ ${ }^{3}$ MTA-SZIE Large Animal Clinical Research Group, Üllö, Hungary
}

(Received 14 April 2015; accepted 22 June 2015)

The aims of this study were to detect physiological changes in blood biochemical parameters throughout gestation, to compare the findings in nonpregnant and pregnant Lipizzaner mares in early-mid and late pregnancy, and to provide reference values for clinical chemistry parameters in this horse breed. A total of 136 venous blood samples were collected from 20 pregnant and 10 nonpregnant (control) asymptomatic Lipizzaner broodmares for biochemical analyses. Twelve parameters (albumin, total protein, urea, triglycerides, glucose, creatinine, alkaline phosphatase, aspartate transaminase, glutamate dehydrogenase, gammaglutamyltransferase, creatine kinase and lactate dehydrogenase) were measured. For the statistical analyses, correlation, analysis of variance and Kruskal-Wallis $\mathrm{H}$-test were used to evaluate the possible associations between parameters. Serum triglyceride levels proved to be significantly different in pregnant mares compared to the control group. Total protein and urea levels significantly decreased, while glucose, triglyceride and glutamate dehydrogenase values increased from approx. the fifth month of gestation until parturition. Four biochemical parameters (albumin, aspartate transaminase, total protein and urea) were lower and three other variables (glucose, alkaline phosphatase and creatinine) were significantly higher in late-term pregnant mares than in mares in early or mid-gestation. It is concluded that reference values not only reflect the species, breed and sex but also the reproductive status of animals.

Key words: Reference values, Lipizzaner pregnant mare, gestation, biochemical parameters, late pregnancy

The values of haematological and biochemical parameters in the peripheral blood change dynamically in physiological and pathological conditions. To provide the highest standard of care, veterinarians require appropriate reference values corresponding to the species, breed, sex and reproductive status of the patient. Recent studies have evaluated haemostatic and haematological changes oc-

*Corresponding author; E-mail: Vincze.Boglarka@aotk.szie.hu; Phone: 0036 (20) 259-4909; Fax: 0036 (29) 521-303 
curring before and after parturition (Bazzano et al., 2014b, 2014c; Vincze et al., 2015). Significant changes could be observed in platelet count, prothrombin time, fibrinogen concentration, as well as in haematocrit, haemoglobin and white blood cell count in connection with foaling (Bazzano et al., 2014b, 2014c). Reference values are available in the scientific literature for adult horses, and several studies have published values for nursing or periparturient mares (Harvey et al., 2005; Aoki and Ishii, 2012) as well as some haematological reference values for stallions, geldings and mares of the Lipizzaner breed (Cebulj-Kadunc et al., 2002), but to the best of our knowledge no biochemical or haematological reference values have been published yet for Lipizzaner mares during gestation. Mariella et al. (2014) have recently conducted a study involving periparturient Standardbred mares and observed some typical changes in blood parameters. Lipizzaners are bred throughout Europe and are well known also in the United States for their favourable properties for coach-driving.

The aims of this study were to detect physiological changes in blood biochemical values throughout gestation and to compare the findings obtained in non-pregnant and pregnant Lipizzaner mares in early to mid- and late pregnancy. Another objective was to provide reference values for blood biochemistry parameters in this horse breed.

\section{Materials and methods}

Animals

Venous peripheral blood was collected from a total of 20 pregnant Lipizzaner mares for biochemical analysis. Ten non-pregnant Lipizzaner mares were used as control. All of the mares are owned by the Hungarian National Stud of Szilvásvárad and were kept and fed under the same circumstances (approx. $2 \mathrm{~kg}$ oats and $6 \mathrm{~kg}$ grass hay during the winter season daily, with unlimited access to water). The mares were moved to the pasture (located at a distance of approx. $3 \mathrm{~km}$ ) twice a day. All animals were considered to be asymptomatic based on their history (6 to 24 years of age, $13 \pm 3$ years [mean $\pm \mathrm{SD}$ ] in both groups) with a body condition score of 5-6 (Body Condition Score Chart, Kentucky Equine Research, USA) during the study. Prior to the study the mares were subjected to thorough physical examination performed by the same veterinarian. All of the pregnant mares had eutocia with viable neonates. Gestational age was calculated from the last artificial insemination (AI, Day 0). Gestational months were counted according to Bucca et al. (2005): first month = days 1 to 30. Pregnancy was detected and confirmed by transrectal ultrasonography between days 20 and 40 after AI by the farm veterinarian. 


\section{Sample collection and preparation}

A total of 136 blood samples ( 1 to 4 samples per mare) were collected, 105 from pregnant mares (days 80 to 330 of gestation, 31 samples in months 3-6 and 74 samples in months $7-11)$. Control samples $(n=31)$ were collected from 10 non-pregnant mares. Horses were bled once every four weeks, from November to March, a total of five times during the sampling period. At the sampling times (once per month), the pregnant mares were at various stages of gestation, because they had been inseminated at different time points in the previous breeding season.

Peripheral blood was collected from the jugular vein on the left side of the neck into tubes containing gel clotting activator (Vacutainer ${ }^{\circledR}$ Serum Tube, BD Medical, USA) using a Number 21 vacuum needle (Vacutainer ${ }^{\circledR}$ Needle, BD Medical, USA). The area of venipuncture was cleaned with ethyl alcohol prior to sampling. To eliminate the influence of circadian changes on blood values, blood sampling was performed between 9 and 12 a.m. Samples were transported to the laboratory in a cooler box as soon as possible (within 6 hours). Serum biochemical analyses were performed in the laboratory of the Department and Clinic of Production Animal Medicine, Faculty of Veterinary Science, Szent István University. Biochemical analysis was performed using an Olympus AU640 ${ }^{\mathrm{TM}}$ Chemistry Immuno Analyzer (Olympus Europe Holding GmbH, Hamburg, Germany) with commercially available colorimetric liquid reagents (Diagnosticum Zrt., Budapest, Hungary) for use on this analyzer.

\section{Blood biochemical analyses}

The following biochemical parameters were measured for all samples: albumin (Alb), total protein (TP), aspartate aminotransferase (AST), alkaline phosphatase (ALP), gamma-glutamyltransferase (GGT), glutamate dehydrogenase (GLDH), glucose (Glu), triglycerides (TG), creatine kinase (CK), lactate dehydrogenase (LDH), urea (Urea), and creatinine (Cre). Quality control measurements were performed each week prior to the measurements. Samples containing visible clots or appearing to be haemolysed were excluded.

\section{Statistical analysis}

Samples collected during early and mid-gestation $(\mathrm{n}=31)$ as well as during late gestation $(n=74)$ and from non-pregnant mares $(n=31)$ were analysed. According to Pagan and Geor (2005), late pregnancy is the period after the seventh month of gestation (from Day 210 to parturition). The results were entered into Microsoft Excel 2007 (Microsoft, California, USA), and all statistical analyses were performed using the free, commercial program R (R Core Team, Vienna, Austria). Correlations between parameters were analysed with the statistics procedure Correlation (associations between maternal and fetal age and bio- 
chemical parameters). If the distribution was Gaussian, the Pearson correlation test, while in other cases the Spearman correlation test was used. When comparing pregnant and non-pregnant mares, the values of these two groups were analysed with Welch's two-sample $t$-test. Comparisons of different time points and months were made with ANOVA or Kruskal-Wallis H-test, or both. Reference values were established according to the recommendations of the International Federation of Clinical Chemistry and the American Society of Veterinary Clinical Pathology (Friedrichs et al., 2005). The distribution of the data was assessed using Shapiro-Wilk and Anderson-Darling tests. If the distribution was Gaussian, the data were analysed with parametric methods; if not, nonparametric (40 $<\mathrm{n}<120)$ or robust $(20<\mathrm{n}<40)$ methods were used. If nonparametric reference intervals could be established, the confidence intervals (CI) of the limits of the nonparametric reference intervals were determined using a bootstrap method. If the sample size was too small $(<40)$ to compute a nonparametric reference interval, data were analysed with the robust method with a Box-Cox transformation after verifying the symmetry. Mean, median, SD, minimum, maximum, lower and upper limits of the reference intervals and 90\% CIs for the lower and upper limits were calculated using the Reference Value Advisor, which is a recent set of macroinstructions for Excel (Microsoft Inc., California, USA). A P value of $<$ 0.05 was considered to be significant.

\section{Results}

The reference values of blood biochemistry parameters measured and calculated in this breed are shown in Table 1. The associations between maternal and fetal age, gestational months, gestational period, the effect of pregnancy itself and serum biochemistry values have been investigated. The factors and their $\mathrm{P}$ values analysed in this study are shown in Table 2 .

The values of most biochemical parameters were found to change with fetal age in this study, with only GGT, CK and LDH values not showing a significant correlation with fetal age. This means that Alb, AST, ALP, TP and Urea values showed a negative correlation over time, but GLDH, TG, Glu and Cre values had a significant positive correlation with fetal age (Table 2).

TG was the only parameter that showed a strongly significant difference between pregnant and non-pregnant mares. Plasma TG concentration was $0.24 \pm 0.08$ $\mathrm{mmol} / \mathrm{L}$ (mean $\pm \mathrm{SD}$ ) in pregnant mares and lower than that, $0.20 \pm 0.08 \mathrm{mmol} / \mathrm{L}$ in control mares (Table 1), with the difference being significant at $\mathrm{P}<0.01$ (Table 2).

Changes according to gestational months could be detected in some parameters: TP and Urea levels were significantly lower from the fourth month of gestation until term and TG increased from the fifth month. Glucose showed significantly increased levels in the last three months in pregnant mares. In the last gestational month, GLDH enzyme activity also increased significantly. 
Table 1

Biochemical reference values in pregnant and non-pregnant (control group) Lipizzaner mares

\begin{tabular}{|c|c|c|}
\hline Parameter & $\begin{array}{l}\text { Pregnant } \\
(\mathrm{n}=105)\end{array}$ & $\begin{array}{l}\text { Non-pregnant (control) } \\
\qquad(\mathrm{n}=31)\end{array}$ \\
\hline \multicolumn{3}{|l|}{ Albumin (g/L) } \\
\hline reference interval & $26.8-37.1$ & $25.8-36.7$ \\
\hline mean & 31.9 & 31.2 \\
\hline median & 31.8 & 31.3 \\
\hline $\mathrm{SD}$ & 2.6 & 2.6 \\
\hline minimum & 25.7 & 26.2 \\
\hline maximum & 38.1 & 37.3 \\
\hline $90 \%$ CI lower limit & $26.1-27.5$ & $24.5-27.1$ \\
\hline $90 \%$ CI upper limit & $36.3-37.8$ & $35.3-38$ \\
\hline \multicolumn{3}{|l|}{ Total protein $(\mathrm{g} / \mathrm{L})$} \\
\hline reference interval & $54.8-82.1$ & $59-80.8$ \\
\hline mean & 68.4 & 69.9 \\
\hline median & 67.9 & 69.8 \\
\hline $\mathrm{SD}$ & 6.8 & 5.3 \\
\hline minimum & 54.2 & 58.8 \\
\hline maximum & 84.6 & 80.7 \\
\hline $90 \%$ CI lower limit & $52.9-56.7$ & $52.9-56.7$ \\
\hline $90 \%$ CI upper limit & $80-84$ & $80-84$ \\
\hline \multicolumn{3}{|l|}{ Urea (mmol/L) } \\
\hline reference interval & $3.3-8$ & $3.1-8.3$ \\
\hline mean & 5.7 & 5.7 \\
\hline median & 5.6 & 5.7 \\
\hline SD & 1.2 & 1.3 \\
\hline minimum & 3.5 & 3.7 \\
\hline maximum & 8.7 & 8 \\
\hline $90 \%$ CI lower limit & $3-3.6$ & $2.5-3.7$ \\
\hline $90 \%$ CI upper limit & $7.7-8.4$ & $7.6-8.9$ \\
\hline \multicolumn{3}{|l|}{ Triglycerides (mmol/L) } \\
\hline reference interval $^{\mathrm{a}}$ & $0.1-0.5^{\mathrm{a}}$ & $0.1-0.4^{\mathrm{a}}$ \\
\hline mean & $0.24^{\mathrm{a}}$ & $0.20^{\mathrm{a}}$ \\
\hline median & 0.2 & 0.2 \\
\hline $\mathrm{SD}$ & 0.08 & 0.08 \\
\hline minimum & 0.09 & 0.06 \\
\hline maximum & 0.52 & 0.46 \\
\hline $90 \%$ CI lower limit & $0.1-0.1$ & $0.0-0.1$ \\
\hline $90 \%$ CI upper limit & $0.4-0.5$ & $0.3-0.4$ \\
\hline \multicolumn{3}{|l|}{ Glucose $(\mathrm{mmol} / \mathrm{L})$} \\
\hline reference interval $^{\mathrm{a}}$ & $3.7-8.1$ & $3.1-7.2$ \\
\hline mean & 5.2 & 5.2 \\
\hline median & 5.0 & 5.1 \\
\hline $\mathrm{SD}$ & 1.1 & 1.0 \\
\hline minimum & 3.64 & 3.74 \\
\hline maximum & 8.41 & 8.03 \\
\hline $90 \%$ CI lower limit & $3.6-3.9$ & $2.8-3.6$ \\
\hline $90 \%$ CI upper limit & $7.8-8.4$ & $6.4-7.9$ \\
\hline
\end{tabular}


Table 1 (continued)

\begin{tabular}{|c|c|c|}
\hline Parameter & $\begin{array}{l}\text { Pregnant } \\
(\mathrm{n}=105)\end{array}$ & $\begin{array}{l}\text { Non-pregnant (control) } \\
\qquad(\mathrm{n}=31)\end{array}$ \\
\hline \multicolumn{3}{|l|}{ Creatinine $(\mu \mathrm{mol} / \mathrm{L})$} \\
\hline reference interval & $77.2-147.1$ & $65.3-135.8$ \\
\hline mean & 103.3 & 100.5 \\
\hline median & 101.5 & 99.2 \\
\hline $\mathrm{SD}$ & 15.3 & 17.0 \\
\hline minimum & 75.1 & 69.2 \\
\hline maximum & 157.1 & 133 \\
\hline $90 \%$ CI lower limit & $75.1-82.2$ & $57.2-73.8$ \\
\hline $90 \%$ CI upper limit & $132.5-157.1$ & $126.8-144.4$ \\
\hline \multicolumn{3}{|c|}{ Alkaline phosphatase (IU/L) } \\
\hline reference interval & $177.7-601.9$ & $141.2-528.1$ \\
\hline mean & 341.9 & 334.7 \\
\hline median & 336.6 & 330.0 \\
\hline SD & 100.7 & 93.2 \\
\hline minimum & 144.8 & 174.9 \\
\hline maximum & 623.9 & 549.5 \\
\hline $90 \%$ CI lower limit & $144.8-203.8$ & $97.2-188.2$ \\
\hline $90 \%$ CI upper limit & $529.9-623.9$ & $478.7-575.3$ \\
\hline \multicolumn{3}{|c|}{ Aspartate aminotransferase (IU/L) } \\
\hline reference interval & $267.7-478.2$ & $241.4-528.4$ \\
\hline mean & 358.7 & 384.9 \\
\hline median & 354.6 & 385.7 \\
\hline $\mathrm{SD}$ & 49.0 & 69.2 \\
\hline minimum & 256.3 & 263.4 \\
\hline maximum & 513.1 & 494 \\
\hline $90 \%$ CI lower limit & $256.3-286.5$ & $218.1-271.3$ \\
\hline $90 \%$ CI upper limit & $438-513.1$ & $496.4-548.2$ \\
\hline \multicolumn{3}{|c|}{ Glutamate dehydrogenase (IU/L) } \\
\hline reference interval & $3.5-9.1$ & $1.4-8.3$ \\
\hline mean & 5.2 & 4.9 \\
\hline median & 4.9 & 4.5 \\
\hline $\mathrm{SD}$ & 1.9 & 1.7 \\
\hline minimum & 3.2 & 2.9 \\
\hline maximum & 19.6 & 10.4 \\
\hline $90 \%$ CI lower limit & $3.2-3.6$ & $0.7-2.7$ \\
\hline $90 \%$ CI upper limit & $7.2-19.6$ & $6.3-9.7$ \\
\hline \multicolumn{3}{|c|}{ Gamma-glutamyltransferase (IU/L) } \\
\hline reference interval & $5.2-19.4$ & $0.3-21.9$ \\
\hline mean & 11.4 & 11.1 \\
\hline median & 11.1 & 10.9 \\
\hline $\mathrm{SD}$ & 3.3 & 5.2 \\
\hline minimum & 0.8 & 4.4 \\
\hline maximum & 21.6 & 34.8 \\
\hline $90 \%$ CI lower limit & $0.8-6.8$ & $3.6-5.6$ \\
\hline $90 \%$ CI upper limit & $17.1-21.6$ & $15.1-28.8$ \\
\hline
\end{tabular}


Table 1 (continued)

\begin{tabular}{lcc}
\hline Parameter & $\begin{array}{c}\text { Pregnant } \\
(\mathrm{n}=105)\end{array}$ & $\begin{array}{c}\text { Non-pregnant (control) } \\
(\mathrm{n}=31)\end{array}$ \\
\hline Creatine kinase (IU/L) & & \\
reference interval & $5.2-19.4$ & $0.3-21.9$ \\
mean & 11.4 & 11.1 \\
median & 11.1 & 10.9 \\
SD & 3.3 & 5.2 \\
minimum & 0.8 & 4.4 \\
maximum & 21.6 & 34.8 \\
$90 \%$ CI lower limit & $0.8-6.8$ & $3.6-5.6$ \\
$90 \%$ CI upper limit & $17.1-21.6$ & $15.1-28.8$ \\
\hline Lactate dehydrogenase (IU/L) & & \\
reference interval & $691.2-1990.2$ & $767.5-1943.2$ \\
mean & 1142.2 & 1188.4 \\
median & 1108.0 & 1140.1 \\
SD & 283.7 & 279.4 \\
minimum & 610.5 & 780.7 \\
maximum & 2295.5 & 1915.8 \\
$90 \%$ CI lower limit & $610.5-797$ & $718.7-842$ \\
$90 \%$ CI upper limit & $1696.8-2295.8$ & $1657.9-2286.9$ \\
\end{tabular}

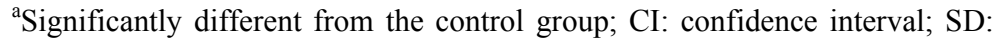
standard deviation

Table 2

Factors affecting the plasma concentrations of biochemical parameters analysed in this study

\begin{tabular}{|c|c|c|c|c|c|}
\hline \multirow[b]{2}{*}{ Parameter } & \multicolumn{5}{|c|}{ Probability $^{*}$} \\
\hline & Maternal age & Fetal age & $\begin{array}{c}\text { Gestational } \\
\text { month } \\
(3-11)\end{array}$ & $\begin{array}{c}\text { Gestational } \\
\text { period } \\
\text { (early-mid, late) }\end{array}$ & $\begin{array}{l}\text { Pregnant vs. } \\
\text { non-pregnant }\end{array}$ \\
\hline ALB & $<0.001$ & 0.0001 & ns & $<0.001$ & ns \\
\hline $\mathrm{TP}$ & $<0.05$ & $<0.0001$ & 0.01 & $<0.0001$ & ns \\
\hline UREA & ns & $<0.00001$ & $<0.01$ & $<0.0001$ & ns \\
\hline TG & ns & $<0.01$ & $<0.05$ & $<0.01$ & $<0.01$ \\
\hline GLUCOSE & ns & $<0.0001$ & $<0.01$ & $<0.001$ & ns \\
\hline CREA & ns & $<0.001$ & ns & $<0.05$ & ns \\
\hline ALP & ns & $<0.01$ & ns & $<0.01$ & ns \\
\hline AST & $<0.001$ & $<0.01$ & ns & $<0.01$ & ns \\
\hline GLDH & $<0.05$ & $<0.001$ & $<0.0001$ & ns & ns \\
\hline GGT & $<0.0001$ & ns & ns & ns & ns \\
\hline $\mathrm{CK}$ & ns & ns & ns & $\mathrm{ns}$ & ns \\
\hline $\mathrm{LDH}$ & ns & ns & ns & ns & ns \\
\hline
\end{tabular}

" significance level; ns: not significantly different $(\mathrm{P}>0.05)$ 
Regarding the period of gestation (early-mid or late pregnancy), Alb, TP, Urea and AST showed decreased levels in late-term pregnant mares as compared to those in early or mid-pregnancy. In contrast, TG, Glu, Cre and ALP values were significantly higher in late-term mares (Table 2).

\section{Discussion}

As blood analysis is an important part of an animal's clinical examination, veterinarians require appropriate reference values for their patients according to species, breed, sex, age and reproductive status to be able to make appropriate treatment decisions. Since pregnancy is a physiological but dynamic state, changes in blood biochemical parameters may occur during this period (e.g. pregnancy affects the cardiovascular system). Although this study was a smallscale investigation because of the limited number of animals and samples involved, studies like this can test hypotheses and their findings can subsequently be used in large-scale programmes.

In our study we analysed the possible associations between biochemical values and the age of fetuses from a clinical perspective. In addition, we made comparisons between values found in pregnant and non-pregnant mares and demonstrated the effect of the gestational period on blood parameters.

The term 'late pregnancy' or 'late gestation' in horses is not clearly defined yet in veterinary medicine according to the available sources. Carleton (2011) defines early equine pregnancy as that lasting until the 6th to 7th month, which is not a clear time point for statistical analysis. Regarding hormonal changes occurring throughout equine pregnancy, the period after day 150 of gestation is defined as late pregnancy (Morel and Davies, 2008). However, we did not find this definition precise enough for describing the late-term development of the equine fetus and the physiological changes occurring in the second half of pregnancy. Therefore, we used the definition of Pagan and Geor (2005) for late gestation, which considers the weight increase and growth curves of the equine fetus. After the seventh month, the equine fetus becomes larger, and it gains approx. $45 \%$ of its birth weight in the last five months before parturition (Pagan and Geor, 2005). Because of the limited number of publications existing in this area regarding pregnant broodmares, we decided to perform statistical analysis of our data, considering also monthly (gestational months) and periodical (earlymid and late pregnancy) changes in biochemical values (Table 2).

Our study confirmed that, comparing all the data of pregnant Lipizzaner mares with those of their non-pregnant stablemates, TG was the only parameter that showed a strongly significant difference between the two groups. As in the second half, or rather the last trimester, of equine pregnancy the fetus is becoming larger, an increased anabolic activity can be detected which can also affect 
fat metabolism. Fat is mobilised to produce enough substances for the growing fetus and the dam, and this process is possibly reflected in the elevated maternal plasma TG levels. Therefore, we had to consider this finding when we established reference values for the Lipizzaner mare population (Table 1). In agreement with earlier studies in ponies and draft mares (Watson et al., 1993; Harvey et al., 2005; Aoki and Ishii, 2012), the plasma triglyceride concentration increased from the fifth month until term. Mariella et al. (2014) reported a similar result in a recent study in Standardbred mares. Glucose regulation is altered during pregnancy towards a progressive development of insulin resistance and a secondary increase in plasma TG levels; this process and the above-mentioned fat mobilisation in the second half of equine gestation can explain this phenomenon.

Interestingly, the values of most biochemical parameters were found to change with fetal age in this study, only GGT, LDH and CK values did not show a significant correlation with fetal age. This means that Alb, AST, ALP, TP and Urea values showed a negative correlation over time, but GLDH, TG, Glu and Cre values had a significant positive correlation with fetal age (Table 2).

Total protein levels (Fig. 1) in the blood decreased significantly from the fourth month of gestation and this tendency continued until the last sampling time in the eleventh month, while albumin remained relatively constant until late pregnancy and then the values of both parameters decreased until term. This is in contrast with the findings of previous studies where TP and Alb levels did not show differences throughout pregnancy (Harvey et al., 2005; Bazzano et al., 2014a), but is consistent with the results found in Standardbred mares in Italy (Mariella et al., 2014). The values of these two proteins were significantly lower in late-term mares than in those in early or mid-pregnancy (Table 2). This may be explained by the fact that close to term, the mammary glands start to produce colostrum, and the primary source of immunoglobulins required for colostrum production is the maternal blood (Hurley and Theil, 2011). The resulting globulin deficit seems to decrease the TP levels in late-term mares; however, as we did not measure blood globulin levels, this change should be investigated further in pregnant mares.

Urea concentrations (Fig. 2) showed a tendency similar to TP, which can be explained by the important role of urea in the anabolic metabolism of nitrogen-containing compounds like proteins; accordingly, decreased TP levels were followed by decreased urea levels. From the fourth month of pregnancy urea levels declined in Lipizzaner mares and this difference could be seen when comparing the two stages of gestation analysed in this study, which is in contrast to findings in other breeds, where either no difference (Harvey et al., 2005) or an elevation (Bazzano et al., 2014a; Mariella et al., 2014) in urea level was found during ongoing pregnancy.

In humans, a physiological increase in glomerular filtration rate (GFR) during pregnancy normally results in a decrease in the concentrations of both se- 
rum creatinine and blood urea nitrogen (BUN). In pregnant women, creatinine also decreases secondary to haemodilution resulting from the $30-50 \%$ plasma expansion by parturition (Maynard and Thadhani, 2009). However, we noted an opposite trend that is concordant with the results of previous studies in horses (Harvey et al., 2005; Aoki and Ishii, 2012). The excretion of fetal creatinine by the dam is a possible cause of this elevation, but Aoki and Ishii (2012) have suggested that these findings might also be related to changes in energy metabolism. According to Mariella et al. (2014), changes in creatinine might reflect an increase in energy demand and a higher demand for amino acids for anabolic processes. In our opinion, the increased work performed by the kidney during gestation may contribute to the elevated plasma creatinine values.

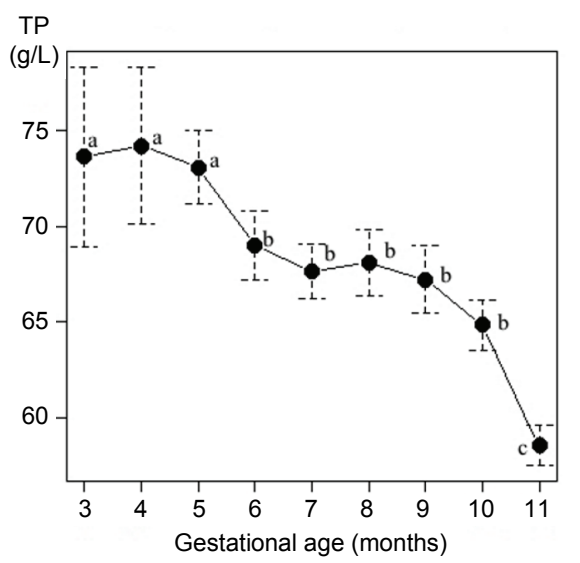

Fig. 1. Mean total protein (TP) levels during gestation (months 3-11) in Lipizzaner mares (values marked $\mathrm{a}, \mathrm{b}$ and $\mathrm{c}$ are significantly different)

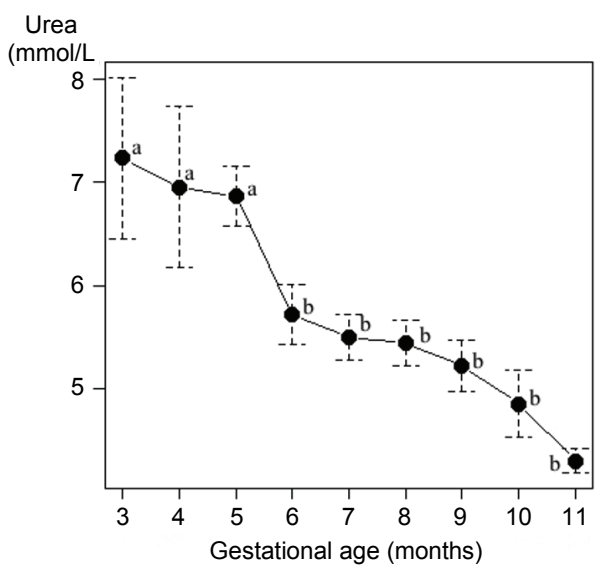

Fig. 2. Mean urea levels during gestation (months 3-11) in Lipizzaner mares (values marked a and $\mathrm{b}$ are significantly different) 
Higher plasma glucose levels were observed in the last three months of gestation, causing significant differences towards parturition in contrast with the findings of an earlier study (Harvey et al., 2005). However, according to other authors (Aoki and Ishii, 2012; Mariella et al., 2014), glucose levels increase near parturition as a result of stress, which also causes elevated blood cortisol levels. Additionally, it has been shown that during pregnancy the dam's cells become somewhat insulin resistant, to allow the transport of glucose through the placenta to the growing fetus (Boden, 1996; Hoffman et al., 2003). In our opinion, the elevation observed in the present study was due to the progression of maternal cell insulin resistance.

Glutamate dehydrogenase (GLDH) activity was significantly higher in late-term pregnant mares than in early to mid-term pregnant mares or in adult horses (Kaneko et al., 1997). This enzyme is present in mitochondria, primarily in liver, nerve and muscle tissues, where it eliminates toxic ammonia (Reed et al., 2004). A possible explanation for this elevation is an increase in metabolic activity (anabolism) of the fetus and the mare during the last trimester of gestation.

Two isoenzymes of aspartate aminotransferase exist: M-AST, which is found exclusively in mitochondria, and C-AST, which originates from the cytoplasm and is mainly found in muscle, liver and myocardial tissues (Krueger et al., 2014). Neither of the two AST isoenzymes shows an apparent tissue specificity, and horses have a significantly higher cytosolic to mitochondrial enzyme ratio than do other species (Krueger et al., 2014). In the present study, AST enzyme activities were significantly lower during late gestation than in early or mid-gestation (Table 2), but were higher than the values reported for adult horses (Kaneko et al., 1997). This is concordant with the findings of earlier studies (Flisińska-Bojanowska et al., 1991; Mariella et al., 2014), in which AST values were lower near term than in non-pregnant mares. The reason remains unclear, but a possible explanation is the strengthening of anabolic processes during this period. As mentioned above, the population studied here showed higher GLDH values in late gestation, which indicates higher glutamate metabolism, and AST is responsible for the transformation of alpha-ketoglutarate to glutamate (Reed et al., 2004). However, multiple isoenzymes of both AST and CK exist, but limitations in the identification of isoenzymes and, thus, their source present a confounding factor that contributes to the measurement of elevated levels of these enzymes. Although multiple tissues may contribute to increases in CK and AST activity, skeletal muscle injury may be the most significant contributor. The higher values of AST observed in this study might be explained by a breed difference or increased exercise, which has already been mentioned in connection with increased CK levels (Krueger et al., 2014).

Gamma-glutamyltransferase is a valuable marker of the hepatobiliary system; the horses in this study showed values lower than those reported for adult horses by others (Kaneko et al, 1997). In other reports, higher GGT activity was 
measured near and during parturition (Gurgoze and Icen, 2010). Interestingly, pregnant women show a slight but significant decrease in GGT during the second and third trimesters of pregnancy, suggesting a hormonal inhibition of hepatic GGT synthesis (Ibdah, 2012).

Creatine kinase activity was found to be much higher than in previous investigations (Kaneko et al., 1997; Mariella et al., 2014) but was affected neither by maternal or fetal age nor by the period of gestation in this study population. $\mathrm{CK}$ has been reported to be lower during late pregnancy than in mid-gestation, but its values were found to be elevated in the periparturient period (Mariella et al., 2014). Aoki and Ishii (2012) suggested that this phenomenon could be explained by a possible trauma in the birth canal during delivery; this may occur but has not been confirmed in normal and undisturbed parturitions. In our opinion, the elevation of CK levels in the absence of disease or trauma may be a feature typical of this Lipizzaner mare population with the aforementioned daily exercise; elevated CK levels develop because of increased muscle CK isoenzyme concentrations (Kobluk et al., 1995).

No significant change in lactate dehydrogenase (LDH) enzyme activity was observed in relation to age or gestation, but the mares studied here showed much higher LDH activities than those in previous reports (Kobluk et al., 1995; Kaneko et al., 1997; Aoki and Ishii, 2012). LDH catalyses the reversible oxidation of pyruvate to lactate (Reed et al., 2004). Five isoenzymes of LDH exist, originating mainly from the heart, liver and skeletal muscle, but almost all tissues contain a certain amount of LDH (Reed et al., 2004). Inflammation, trauma, toxic myopathies and severe hepatic failure can cause elevated LDH levels (Reed et al., 2004), but these causes cannot explain the high LDH activities that we found in an asymptomatic population. Because red blood cells have high LDH activity, a false increase in LDH level can be caused by mild haemolysis or lipaemia in a specimen (Kobluk et al., 1995). Increased levels may indicate that the horse has undergone intense exercise without indicating damage (Kobluk et al., 1995). In our opinion, the elevated levels observed in this study are physiological and were caused by the daily movement of the mares to the pasture (see Materials and methods).

In agreement with the findings of other studies (Meuten et al., 1980; Mariella et al., 2014), alkaline phosphatase (ALP), which is present in several tissues (mostly in the liver and bones), did not change during pregnancy, but the values were higher than those reported for adult horses by others (Kaneko et al., 1997). According to Gaál (1999), ALP activity can be higher in late pregnancy in mammals because during this anabolic period the activity of osteoclastic cells is higher, and because ALP can be produced by the placenta as well. 


\section{Acknowledgements}

We would like to thank Tamás Mikó, Andor Dallos, Károly Bácsi, Sándorné Tani and Ernőné Sípos for their technical help during the field and laboratory measurements. This study was partly funded by the Department and Clinic of Production Animal Medicine, Faculty of Veterinary Science, Szent István University and by the Hungarian Academy of Sciences.

\section{References}

Aoki, T. and Ishii, M. (2012): Hematological and biochemical profiles in peripartum mares and neonatal foals (heavy draft horse). J. Equine Vet. Sci. 32, 170-176.

Bazzano, M., Gianetto, C., Fazio, F., Arfuso, F., Giudice, E. and Piccione, G. (2014a): Metabolic profile of broodmares during late pregnancy and early post-partum. Reprod. Dom. Anim. 49, 947-953.

Bazzano, M., Gianetto, C., Fazio, F., Marafioti, S., Giudice, E. and Piccione, G. (2014b): Haemostatic profile during late pregnancy and early postpartum period in mares. Theriogenology 81, 639-643.

Bazzano, M., Gianetto, C., Fazio, F., Rizzo, M., Giudice, E. and Piccione, G. (2014c): Physiological adjustments of haematological profile during the last trimester of pregnancy and the early post partum period in mares. Anim. Reprod. Sci. 149, 199-203.

Boden, G. (1996): Fuel metabolism in pregnancy and in gestational diabetes mellitus. Obstet. Gynecol. Clin. North Am. 23, 1-10.

Bucca, S., Fogarty, U., Collins, A. and Small, V. (2005): Assessment of feto-placental well-being in the mare from mid-gestation to term: Transrectal and transabdominal ultrasonographic features. Theriogenology 64, 542-557. Proceedings of the 2005 Annual Conference of the Society for Theriogenology.

Carleton, C. L. (2011): Blackwell's Five-Minute Veterinary Consult Clinical Companion: Equine Theriogenology. John Wiley \& Sons, Philadelphia.

Cebulj-Kadunc, N., Bozic, M., Kosec, M. and Cestnik, V. (2002): The influence of age and gender on haematological parameters in Lipizzan horses. J. Vet. Med. A 49, 217-221.

Flisińska-Bojanowska, A., Komosa, M. and Gill, J. (1991): Influence of pregnancy on diurnal and seasonal changes in glucose level and activity of FDPA, AlAT and AspAT in mares. Comp. Biochem. Physiol. A Comp. Physiol. 98, 31-35.

Friedrichs, K., Barnhart, K., Blanco, J., Freeman, K., Harr, K., Szladovits, B. and Walton, R. (2005): ASVCP Quality Assurance and Laboratory Standards Committee (QALS) Guidelines for the Determination of Reference Intervals in Veterinary Species and Other Related Topics. Am. Soc. Vet. Clin. Path. URL http://www.asvep.org/pubs/pdf/RI\%20Guidelines\% 20For\%20ASVCP\%20website.pdf

Gaál, T. (ed.) (1999): Állatorvosi klinikai laboratóriumi diagnosztika [Veterinary Clinical Laboratory Diagnostics (in Hungarian)]. Sík Kiadó, Budapest.

Gurgoze, S. Y. and Icen, H. (2010): The influence of age on clinical biochemical parameters in pure-bred Arabian mares. J. Equine Vet. Sci. 30, 569-574.

Harvey, J. W., Pate, M. G., Kivipelto, J. and Asquith, R. L. (2005): Clinical biochemistry of pregnant and nursing mares. Vet. Clin. Pathol. 34, 248-254.

Hoffman, R. M., Kronfeld, D. S., Cooper, W. L. and Harris, P. A. (2003): Glucose clearance in grazing mares is affected by diet, pregnancy, and lactation. J. Anim. Sci. 81, 1764-1771.

Hurley, W. L. and Theil, P. K. (2011): Perspectives on immunoglobulins in colostrum and milk. Nutrients 3, 442-474. 
Ibdah, J. A. (2012): Maternal Liver Disease. Landes Bioscience, Austin. http://www.landesbioscience.com/ iu/Ibdah_9781587066757.pdf

Kaneko, J. J., Harvey, J. W. and Bruss, M. (1997): Clinical Biochemistry of Domestic Animals. 5th edition. Academic Press, San Diego.

Kobluk, C. N., Ames, T. R. and Geor, R. J. (1995): Clinical evaluation of muscle and muscular disorders. In: Kobluk, C. N., Maes, T. K. and Geor, R. J. (eds) The Horse: Diseases and Clinical Management. W. B. Saunders, Philadelphia. pp. 1314-1318.

Krueger, C. R., Ruple-Czerniak, A. and Hacket, E. S. (2014): Evaluation of plasma muscle enzyme activity as an indicator of lesion characteristics and prognosis in horses undergoing celiotomy for acute gastrointestinal pain. BMC Vet. Res. 10 (Suppl. 1), S7. doi: http://www.biomedcentral.com/1746-6148/10/S1/S7

Mariella, J., Pirrone, A., Gentilini, F. and Castagnetti, C. (2014): Hematologic and biochemical profiles in Standardbred mares during peripartum. Theriogenology 81, 526-534.

Maynard, S. E. and Thadhani, R. (2009): Pregnancy and the kidney. J. Am. Soc. Nephrol. 20, 14-22.

Meuten, D. J., Kociba, G., Threlfall, W. R. and Nogode, L. A. (1980): Serum alkaline phosphatase in pregnant mares. Vet. Clin. Pathol. 9, 27-30.

Morel, M. and Davies, C. G. (2008): Equine Reproductive Physiology, Breeding and Stud Management. CABI Publishing, New York.

Pagan, J. D. and Geor, R. J. (2005): Advances in Equine Nutrition III. Nottingham University Press, Nottingham.

Reed, S. M., Bayly, W. M. and Sellon, D. C. (eds) (2004): Equine Internal Medicine. 2nd edition. W. B. Saunders, Philadelphia.

Vincze, B., Baska, F. and Szenci, O. (2015): Pregnancy-associated changes in haematological parameters in Lipizzaner broodmares [in Hungarian, with English abstract]. Magyar Állatorvosok Lapja 137, 195-202.

Watson, T. D., Burns, L., Packard, C. J. and Shepherd, J. (1993): Effects of pregnancy and lactation on plasma lipid and lipoprotein concentrations, lipoprotein composition and postheparin lipase activities in Shetland pony mares. J. Reprod. Fertil. 97, 563-568. 